\title{
Research on Properties of High-Performance Cement Mortar for Semiflexible Pavement
}

\author{
Yazhen Sun $\mathbb{D}^{1},{ }^{1}$ Yuanyuan Cheng, ${ }^{1}$ Min Ding, ${ }^{2}$ Xuezhong Yuan $\mathbb{D D}^{3}$ and Jinchang Wang ${ }^{4}{ }^{4}$ \\ ${ }^{1}$ School of Transportation Engineering, Shenyang Jianzhu University, Shenyang 110168, China \\ ${ }^{2}$ Zhejiang Scientific Research Institute of Transport, Zhejiang Province, Hangzhou 310009, China \\ ${ }^{3}$ School of Science, Shenyang Jianzhu University, Shenyang 110168, China \\ ${ }^{4}$ Institute of Transportation Engineering, Zhejiang University, Hangzhou 310058, China \\ Correspondence should be addressed to Yazhen Sun; syz16888@126.com
}

Received 26 June 2018; Accepted 17 September 2018; Published 16 October 2018

Academic Editor: Luigi Nicolais

Copyright (C) 2018 Yazhen Sun et al. This is an open access article distributed under the Creative Commons Attribution License, which permits unrestricted use, distribution, and reproduction in any medium, provided the original work is properly cited.

\begin{abstract}
Cement mortar is one of the most important components of semiflexible pavement materials; however, the effects of cement mortar formulation on the performance and the grouting rate are rarely studied. Therefore, the optimum formulation of highperformance cement mortar (HPCM) for different types and contents was studied, and the grouting effect of the cement mortar was studied by rutting tests. The results show that polycarboxylate superplasticizer, expansion admixture, and accelerating admixture have different influences on the workability, the strength, and the drying shrinkage of HPCM, and the working ability of HPCM is good by adding these three admixtures. The strength at 7 days is 1.3 to 4 times that of the existing specifications, and the shrinkage rate is less than 0.2 . The HPCM has higher early strength, and the strength development is stable in the later period compared with the other research studies. The semiflexible material has better pavement performance when the grouting rate is greater than $90 \%$.
\end{abstract}

\section{Introduction}

With the increasing traffic flow and traffic loads, early problems like deformation usually appear on traditional asphalt roads [1]. In order to improve pavement performance and prolong the life of roads, semiflexible pavement concept has been proposed and studied.

Semiflexible pavement is a composite pavement made by pouring cement slurry into a porous asphalt mixture with the porosity between $20 \%$ and $28 \%$ [2]. The pavement is a new type of pavement which combines the advantages of rigid cement concrete pavement and flexible asphalt pavement [3]. The semiflexible pavements have been applied to roads, airfields, sea ports, and industrial heavy-loading yards on account of their excellent rutting resistance, fatigue resistance, abrasion resistance, oil resistance, and colorability [4]. It was considered to be much stiffer and resistant to traffic-induced damage compared to conventional asphalt pavement [5]. The semiflexible pavement has been selected to resist deformation, thereby reducing the maintenance costs [6]. Therefore, the most important part of the technology is the combination of the advantages between the flexible asphalt pavement and the rigid cement concrete pavement.

Semiflexible material was first studied and applied in France [7]. Subsequently, the semiflexible pavements in Britain, the United States, and the former Soviet Union were studied and were confirmed to have high temperature stability $[8,9]$. Many research studies have been performed by researchers on the performances of the semiflexible materials. The influences of different factors on the damage were analyzed, and the relational model of loading times and damage variable was established according to cyclic wheel load tests [10]. The performance differences in the compressive strength, the indirect tensile stiffness, and the dynamic creep tests of the semiflexible pavement paved both with the cool-mixed method and the traditional hot-mixed method have been studied [11]. The experience with heavy 
vehicle simulator (HVS) has been used to study the hazards of the weak layer of the semiflexible pavement and its modeling $[12,13]$.

In China, the research on methods of the semiflexible material design has been carried out [14]. The influences of asphalt mixture types and porosity on the performance of semiflexible pavement materials were studied $[15,16]$. The proportion of compound mortar required to meet the construction requirement was researched [17]. The optimization design of the ratio of cement mortar to cement injection was studied [18]. The influence of different factors on the fluidity of cement mortar was also studied [19].

Up to now, the research studies of semiflexible pavement materials were mainly focused on the differences between the semiflexible pavement and other traditional pavements in terms of the mixture designs, the structures, and the mechanical performance, but the effects of grouting materials were less studied. So far, the studies on cement mortars in China have adopted the technical specifications in the Technology Guide for Application of Semi-Flexible Pavement [20], and the strengths of cement mortars at 7 days and 28 days were studied, but no further studies were conducted on the low-age strength of cement mortar. Besides, the strength of the grouting material was low, the curing was slow, and large shrinkage crackings tend to occur, resulting in a long construction period and affecting the road performance [21].

In this paper, three cement additives were selected and mixed into the cement mortar to prepare for different types of HPCM, and the effects of additives on the workability, the drying shrinkage, and the strength with different curing times of HPCM were analyzed to determine the suitable range of the mixing ratio. Furthermore, the properties of the workability, the strengths with different curing times, and the drying shrinkages of HPCM with the optimal formulation were verified. Then, the rut resistance of the best formulation with different grouting rates was studied.

\section{Materials and Experimental}

2.1. Cement Mortar. In this study, the Conch Brand 42.5 Ordinary Portland cement, produced in Anhui, China, was used which meets the technical requirements in the Test Methods of Cement and Concrete for Highway Engineering, China (JTG E30-2005) [22], and its major chemical and physical properties are shown in Table 1. The standard sand was produced by Chinese ISO Standard Sand Co, Ltd. The grading and $\mathrm{SiO}_{2}$ content meet the relevant domestic technical requirements, and the $\mathrm{SiO}_{2}$ content is greater than $98.0 \%$. The physical properties of the limestone mineral powder are listed in Table 2.

In this study, three kinds of admixtures were used to manufacture the high-performance cement mortar; they were the UEA expansion admixture, the high-performance polycarboxylate water reducer, and the accelerating admixture. The UEA expansion admixture is a yellow powder with a water content of $0.96 \%$, a total alkali of $0.2 \%$, a chlorine ion content of $0.9 \%$, a specific surface area of $327 \mathrm{~m}^{2} / \mathrm{kg}$, and a $\mathrm{MgO}$ content of $2.74 \%$. The polycarboxylate superplasticizer is a light brown liquid with a solid content of $24.14 \%$, a water reduction rate of $28.5 \%$, a density of $1.09 \mathrm{~g} / \mathrm{cm}^{3}$, a $\mathrm{pH}$ of 7.5 , and a chlorine ion content of $1 \%$. The accelerating admixture is a liquid with a solid content of $57.14 \%$, a density of $1.421 \mathrm{~g} / \mathrm{cm}^{3}$, a $\mathrm{pH}$ of 13.4 , and a chlorine ion content of $1.02 \%$.

2.2. Porous Asphalt Mixture. According to the specifications [23] and engineering experience, the porous asphalt mixture is formed by mixing the aggregate of SFAC-13 (SemiFlexible Asphalt Concrete-13) grading and SBS modified bitumen with a designed porosity of $25 \%$, and the aggregate is basalt. The aggregate grading is listed in Table 3, and the modified asphalt has a penetration of $50.5 \mathrm{~mm}(100 \mathrm{~g}, 5 \mathrm{~s}$, $25^{\circ} \mathrm{C}$ ), a softening point of $75.6^{\circ} \mathrm{C}$, and a ductility of $32 \mathrm{~cm}$ at $5^{\circ} \mathrm{C}$. The asphalt content determined by flying test and leak detection test is $3.8 \%$, the Marshall stability is $5.01 \mathrm{kN}$, and the actually measured porosity of the porous asphalt mixture is $24.6 \%$.

\subsection{High-Performance Cement Mortar (HPCM) Sample} Preparation. Cement mortar should be able to penetrate the porous asphalt mixture quickly to improve the strength of the composite. According to the design ratio, each admixture was added into the cement slurry, and they were mixed to make the cement mortar. The cement mortar was poured into the standard test mold for the strength, the shrinkage, and the workability experiments according to the specifications [22].

It is shown that the optimum water-binder ratio of the prime cement mortar that was used to semiflexible pavement should be less than 0.55 [24], the content of mineral powder is generally less than $20 \%$, and the sand content is approximately $15 \%-30 \%$. The factors of the cement mortar are the water-binder ratio, the content of mineral powder, the sand-binder, the UEA expansion admixture, the polycarboxylate superplasticizer, and the accelerating admixture, represented by $A, B, C, D, E$, and $F$, respectively. Three levels were selected for each of the factors, and the effects of which on the physical and mechanical properties of the cement mortar were analyzed. The orthogonal factors for the cement slurry are listed in Table 4.

2.4. Calculation of Grouting Rate of Cement Mortar. The grouting rate of cement mortar is the percentage of the volume of cement mortar grouted divided by the volume of connected void in the asphalt mixture, and the formula is

$$
\mathrm{VV}=\frac{m_{2}-m_{1}}{\rho_{\mathrm{m}}\left(V-V_{1}\right)} \times 100,
$$

where $\mathrm{VV}$ is the grouting rate $(\%), m_{1}$ is the mass of the specimen before grouting $(\mathrm{g}), m_{2}$ is the mass of the sample after grouting $(\mathrm{g}), \rho_{\mathrm{m}}$ is the density of the cement mortar $\left(\mathrm{g} / \mathrm{cm}^{3}\right), V$ is the specimen volume $\left(\mathrm{cm}^{3}\right)$, and $V_{1}$ is the volume of mineral aggregate and closed pores $\left(\mathrm{cm}^{3}\right)$. 
Table 1: Chemical and physical properties of Portland cement.

\begin{tabular}{|c|c|c|c|c|c|c|c|}
\hline $\begin{array}{l}\text { ical } \\
\text { sis }\end{array}$ & $\begin{array}{l}\text { Test } \\
\text { Test }\end{array}$ & $\begin{array}{l}\mathrm{SO}_{3} \\
2.7 \% \\
\end{array}$ & $\begin{array}{l}\mathrm{MgO} \\
2.0 \% \\
\end{array}$ & $\begin{array}{c}\mathrm{SiO}_{2} \\
25.4 \% \\
\end{array}$ & $\begin{array}{c}\mathrm{A}_{2} \mathrm{O}_{3} \\
9.3 \% \\
\end{array}$ & & $\begin{array}{l}\text { ss on ignition } \\
2.2 \% \\
\end{array}$ \\
\hline $\begin{array}{l}\text { hysical } \\
\text { ests }\end{array}$ & $\begin{array}{l}\text { Test items } \\
\text { Test results }\end{array}$ & $\begin{array}{l}\text { Initial setting } \\
\text { time } \\
183\end{array}$ & $\begin{array}{l}\text { inal setting } \\
\text { time } \\
241\end{array}$ & $\begin{array}{c}3 \text { days' compress } \\
\text { strength } \\
24.9\end{array}$ & $\begin{array}{l}3 \text { days' flexural } \\
\text { strength } \\
2.8\end{array}$ & $\begin{array}{c}28 \text { days' compr } \\
\text { strength } \\
49.2\end{array}$ & $\begin{array}{c}28 \text { days' flexural } \\
\text { strength } \\
7.9\end{array}$ \\
\hline
\end{tabular}

TABle 2: Physical properties of mineral powder.

\begin{tabular}{|c|c|c|c|c|c|c|c|c|c|}
\hline \multirow[t]{2}{*}{ Physical tests } & \multirow{2}{*}{$\begin{array}{c}\text { Apparent relative } \\
\text { density }\end{array}$} & \multirow{2}{*}{$\begin{array}{l}\text { Moisture } \\
\text { content }\end{array}$} & \multirow[t]{2}{*}{ Appearance } & \multirow{2}{*}{$\begin{array}{l}\text { Hydrophilic } \\
\text { coefficient }\end{array}$} & \multirow{2}{*}{$\begin{array}{l}\text { Plasticity } \\
\text { index }\end{array}$} & \multicolumn{4}{|c|}{$\begin{array}{c}\text { Gradation } \\
\text { Passing rate }(\%)\end{array}$} \\
\hline & & & & & & $0.6 \mathrm{~mm}$ & $0.3 \mathrm{~mm}$ & $0.15 \mathrm{~mm}$ & $0.075 \mathrm{~mm}$ \\
\hline Test results & 2.692 & $0.23 \%$ & Ununited particle & $0.46 \%$ & 2.3 & 100 & 96.9 & 91.6 & 80.94 \\
\hline
\end{tabular}

TABLE 3: Aggregate grading for porous mix.

\begin{tabular}{lccccccccccc}
\hline Mesh size $(\mathrm{mm})$ & 100 & 13.2 & 9.5 & 4.75 & 2.36 & 1.18 & 0.6 & 0.3 & 0.15 & 0.075 \\
\hline Passing rate $(\%)$ & 100 & 95 & 18 & 12 & 10 & 8.5 & 8 & 6.5 & 6 & 4 \\
\hline
\end{tabular}

TABLE 4: Factor level of HPCM.

\begin{tabular}{lcccccc}
\hline $\begin{array}{l}\text { Factor } \\
\text { level }\end{array}$ & $\begin{array}{c}\text { A: Water-binder } \\
\text { ratio (W/B) }\end{array}$ & $\begin{array}{c}\text { B: Content of } \\
\text { mineral powder (\%) }\end{array}$ & $\begin{array}{c}\text { C: Sand-binder } \\
\text { ratio }\end{array}$ & $\begin{array}{c}D \text { : UEA expansion } \\
\text { admixture } \\
\text { content (\%) }\end{array}$ & $\begin{array}{c}\text { E: polycarboxylate } \\
\text { superplasticizer } \\
\text { content (\%) }\end{array}$ & $\begin{array}{c}F: \text { accelerating } \\
\text { admixture content (\%) }\end{array}$ \\
\hline 1 & 0.45 & 10 & 0.15 & 0 & 0 & 0 \\
2 & 0.5 & 15 & 0.2 & 4 & 0.5 & 0.5 \\
3 & 0.55 & 20 & 0.25 & 8 & 1 & 1 \\
\hline
\end{tabular}

\subsection{Preparation of Specimens for Grouting Composite} Materials. The composite grouting is the asphalt mixture filled with cement mortar, and the rutting slab of composite grouting was formed by filling open porosity asphalt mixture with cement mortar. The specific pouring processes are as follows:

Firstly, $300 \mathrm{~mm} \times 300 \mathrm{~mm} \times 50 \mathrm{~mm}$ rutting slabs were prepared using the porous asphalt mixture, and then they were cooled down at room temperature. Secondly, HPCM specimens were prepared through uniform mixing. Thirdly, the grouting materials with different masses were grouted into rutting slabs when the temperature of the rutting slabs was dropped to $60^{\circ} \mathrm{C}$. Specifically, the rutting slabs were placed on the concrete vibration table. Then, the cement mortar was uniformly poured on the surface of the rutting slabs, and the vibration table was opened to vibrate until the mortar was no longer infiltrated. Finally, the excess grouting material was scraped off by using a rubber scraper and brushed lightly until exposing the uneven surface of the asphalt mixture. The specimen shown in Figure 1 was removed from molds after curing for 24 to 48 hours until the grouting material was hardened and then cured for 7 days in the room.

\subsection{Test Methods}

2.6.1. Test Methods of the Workability. It was determined by the workability whether the cement mortar could fully

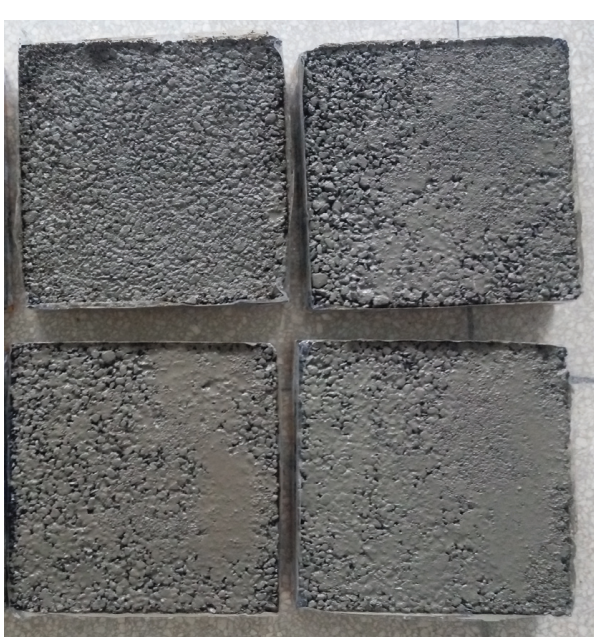

FigURE 1: Specimens after grouting.

penetrate into the porous asphalt mixture skeleton and fill all the accessible voids. The workability test was conducted according to the Standard Test Method for Flow of Grout for Cement Mortar-Flow Cone Method (JTG E30/T 05082005, China) [22].

2.6.2. Test Methods of the Drying Shrinkage. The drying shrinkage was conducted according to the Standard Test Method for Drying Shrinkage of Cement Mortar (JTG E30/T 
0511-2005, China) [22], and the drying shrinkage value of the specimen at 28 days was used as the evaluation index.

2.6.3. Test Methods of Strengths. The compressive and flexural strength tests were the most basic strength test of cement concrete materials which were used as the main property indicator to characterize cement materials' quality. The strength tests were conducted according to the Method of Testing Cements for Determination of Strength-ISO Method (JTG E30/T 0506-2005, China) [22].

\section{Test Results and Analysis of HPCM}

The workability, the dry shrinkage, and the strengths of the materials with different curing times are considered as evaluation indexes for grouting materials, and the results of the range analysis of the HPCM indicators are listed in Table 5.

3.1. Analysis of the Workability on HPCM. As shown in Table 4, the factors affecting the workability, in the order of importance, are the polycarboxylate superplasticizer, the water-binder ratio, the accelerating admixture, the expansion admixture, the mineral powder, and the sand-binder ratio, and their weight ratios are $28.18 \%, 25.75 \%, 17.97 \%$, $11.49 \%, 8.28 \%$, and $7.69 \%$, respectively. The results show that the polycarboxylate superplasticizer content and waterbinder ratio are more important compared with other factors, and the sand-binder ratio is of least importance of the factors.

3.2. Analysis of the Drying Shrinkage on HPCM. During the hardening process, dry shrinkage of the cement mortar would occur, resulting in the emergence of the fine cracks inside the semiflexible pavement. Therefore, the cement mortar must have certain volume stability.

As shown in Table 4, the factors affecting the dry shrinkage, in the order of importance, are the expansion admixture, the sand-binder ratio, the mineral powder, the accelerating admixture, the polycarboxylate superplasticizer, and the water-binder ratio, and their weight ratios are $36.83 \%, 19.25 \%, 15.95 \%, 13.45 \%, 7.37 \%$, and $7.14 \%$, respectively. The results show that the expansion admixture content is the most important compared with other admixture contents, and the polycarboxylate superplasticizer and the water-binder ratio are of least importance of the factors.

3.3. Analysis of Strengths on HPCM. As shown in Table 4, the factors affecting the 1 day flexural strength, in the order of importance, are the expansion admixture content, the accelerating admixture content, the water-binder ratio, the polycarboxylate superplasticizer content, the content of the mineral powder, and the sand-binder ratio, and their weight ratios are $22.52 \%, 19.45 \%, 18.95 \%, 15.07 \%, 14.08 \%$, and $9.93 \%$, respectively. The factors affecting the 1 day compressive strength, in the order of importance, are the water-binder ratio, the polycarboxylate superplasticizer content, the expansion admixture content, the accelerating admixture content, the sand-binder ratio, and the mineral powder content, and their weight ratios are $22.52 \%, 19.45 \%$, $18.95 \%, 15.07 \%, 14.08 \%$, and $9.93 \%$, respectively.

The results suggest that the water-binder ratio, the expansion admixture, and the polycarboxylate superplasticizer have great effects on the 1 day strength of HPCM, and their importance is nearly the same. However, the sand-binder ratio and the mineral powder content have the least effects on the 1 day strength of HPCM.

The factors affecting the 3 days' flexural strength, in the order of importance, are the expansion admixture content, the polycarboxylate superplasticizer content, the accelerating admixture content, the water-binder ratio, the sandbinder ratio, and the mineral powder content, and their weight ratios are $26.63 \%, 26.42 \%, 13.35 \%, 12.74 \%, 11.17 \%$, and $9.70 \%$, respectively. The factors affecting the 3 days' compressive strength, in the order of importance, are the polycarboxylate superplasticizer content, the water-binder ratio, the sand-binder ratio, the expansion admixture content, the mineral powder content, and the accelerating admixture content, and their weight ratios are $38.88 \%$, $19.91 \%, 12.90 \%, 12.71 \%, 11.71 \%$, and $3.89 \%$, respectively.

The above results show that the expansion admixture and the polycarboxylate superplasticizer have a great influence on the 3 days' strength of HPCM, the water-binder ratio and the sand-binder ratio have a slight influence, and the mineral powder content and the accelerating admixture content have a weak influence on the 3 days' strength of HPCM.

The factors affecting the 7 days' flexural strength, in the order of importance, are the polycarboxylate superplasticizer content, the expansion admixture content, the water-binder ratio, the accelerating admixture content, the sand-binder ratio, and the mineral powder content, and their weight ratios are $24.44 \%, 22.26 \%, 18.24 \%, 13.60 \%, 11.32 \%$, and $10.14 \%$, respectively. The factors affecting the 7 days' compressive strength, in the order of importance, are the polycarboxylate superplasticizer content, the water-binder ratio, the sand-binder ratio, the mineral powder content, the expansion admixture content, and the accelerating admixture content, and their weight ratios are $41.41 \%, 26.67 \%$, $16.78 \%, 7.60 \%, 4.60 \%$, and $2.94 \%$, respectively.

The above results show that the polycarboxylate superplasticizer content has the greatest effects on the 7 days' strength of HPCM, and the mineral powder content and the accelerating admixture content have a weak influence on the 7 days' strength of HPCM.

The factors affecting the 28 days' flexural strength, in the order of importance, are the polycarboxylate superplasticizer content, the water-binder ratio, the expansion admixture content, the sand-binder ratio, the mineral powder content, and the accelerating admixture content, and their weight ratios are $22.46 \%, 22.29 \%, 20.68 \%, 18.15 \%, 9.27 \%$, and $7.15 \%$, respectively. The factors affecting the 28 days' compressive strength, in the order of importance, are the polycarboxylate superplasticizer content, the water-binder ratio, the sand-binder ratio, the expansion admixture 
TABLE 5: The range result of HPCM.

\begin{tabular}{|c|c|c|c|c|c|c|c|}
\hline & & $A$ & $B$ & C & $D$ & E & $F$ \\
\hline Fluidity (s) & & 15.28 & 4.92 & 4.57 & 6.82 & 17.10 & 10.67 \\
\hline Dry shrinkage(0.001) & & 0.160 & 0.358 & 0.432 & 0.826 & 0.165 & 0.302 \\
\hline \multirow{2}{*}{1 day strength $(\mathrm{MPa})$} & Flexural strength & 1.58 & 1.18 & 0.83 & 1.88 & 1.26 & 1.63 \\
\hline & Compressive strength & 11.75 & 2.89 & 3.64 & 10.18 & 11.39 & 5.89 \\
\hline \multirow{2}{*}{3 days' strength $(\mathrm{MPa})$} & Flexural strength & 1.70 & 1.30 & 1.49 & 3.56 & 3.53 & 1.78 \\
\hline & Compressive strength & 8.75 & 5.15 & 5.67 & 5.59 & 17.09 & 1.71 \\
\hline \multirow{2}{*}{7 days' strength (MPa) } & Flexural strength & 2.59 & 1.44 & 1.61 & 3.16 & 3.47 & 1.93 \\
\hline & Compressive strength & 14.68 & 4.19 & 9.24 & 2.53 & 22.80 & 1.62 \\
\hline \multirow{2}{*}{28 days' strength $(\mathrm{MPa})$} & Flexural strength & 2.26 & 0.94 & 1.84 & 2.10 & 2.28 & 0.72 \\
\hline & Compressive strength & 15.08 & 2.41 & 10.93 & 2.84 & 18.84 & 1.57 \\
\hline
\end{tabular}

content, the mineral powder content, and the accelerating admixture content, and their weight ratio are $36.46 \%$, $29.18 \%, 21.15 \%, 5.51 \%, 4.66 \%$, and $3.03 \%$, respectively.

The above results show that the polycarboxylate superplasticizer and the water-binder ratio possess a great influence on the 28 days' strength of HPCM, the sand-binder ratio and the expansion admixture have a slight influence, and the mineral powder and the accelerating admixture have the worst influence on the 28 days' strength of HPCM.

The flexural strength of HPCM is mainly affected by the expansion admixture content and the accelerating admixture content, followed by the polycarboxylate superplasticizer content and the water-binder ratio. After the reaction of the accelerating admixture and the expansion admixture is completed, their influence on the flexural strength is weakened, while the polycarboxylate superplasticizer content and the water-binder ratio begin to influence the flexural strength with the increase of curing time. The water-binder ratio and the polycarboxylate superplasticizer content are the main factors influencing the compressive strength of HPCM, and the influences of the expansion admixture content and the accelerating admixture content on the compressive strength of HPCM gradually weakened with the reaction when the curing time is increasing. The effect of the sand-binder ratio on the strength gradually increased in the later stage of curing.

The above analysis shows that the polycarboxylate superplasticizer content and the water-binder ratio have the greatest influence on strength of HPCM. The expansion and the accelerating admixture have a greater influence on the low-age strength, and the sand-binder ratio has a greater influence on the strength at the later stage of curing. The mineral powder has the least effect on the strength of HPCM.

\section{Influence Tendencies of Factors on Properties of HPCM}

4.1. Influence Tendencies of Factors on Workability of HPCM. According to the experimental results, the influence tendencies of all factors on workability are shown in Figure 2.

It can be seen that the fluidity decreases with the increase of the water-binder ratio. The fluidity drops rapidly when the water-binder ratio varies from 0.45 to 0.50 , and the workability performance is better when the water-binder ratio varies from 0.50 to 0.55 . The fluidity at the 0.45 water-binder ratio is 28s, and the fluidity decreases by $53 \%$ when the water-binder ratio is 0.55 . Therefore, the optimum range of the water-binder ratio is $0.5-0.55$. The fluidity increases with the mineral powder content, and it reduces by $24 \%$ compared with the content of 0.2 , when the content of the mineral powder is 0.1 . The fluidity increases first and then decreases with the increase of the sand-binder ratio, and the workability is the optimum when the sand-binder ratio is 0.2 .

The fluidity increases first and then decreases with the increase of the expansion admixture content. The fluidity of the cement mortar is larger than that of the pure cement mortar as the expansion admixture is added, and this indicates that the workability can be reduced to a certain extent by adding the expansion admixture. However, the influence of the expansion admixture on the workability decreases with the increase of the expansion admixture content, and the fluidity starts to decrease.

The fluidity increases first and then decreases with the increase of the polycarboxylate superplasticizer content, and the fluidity is the optimum when there is no polycarboxylate superplasticizer. The reason is that the unit water consumption decreases after the addition of the polycarboxylate superplasticizer, resulting in the increase of the fluidity [25]. The cement particles are completely dispersed when the superplasticizer content exceeds a certain value, reducing the fluidity of the cement mortar. Therefore, the optimum polycarboxylate superplasticizer content is greater than 0.01 .

The fluidity decreases first and then increases with the increase of the content of the accelerating admixture. The fluidity of the cement mortar is smaller than that of the pure cement mortar as the expansion admixture is added, and this indicates that the workability can be reduced to a certain extent by adding the accelerating admixture. However, the influence of the accelerating admixture content on the workability decreases with the increase of the content. The reason is that the cement mortar cannot be hardened quickly when the content of the accelerating admixture is low, and the water-binder ratio increases with the water content in the accelerating admixture, resulting in the increase of the workability. However, the mortar can hydrate and harden quickly when the accelerating admixture content is higher, and the workability of the cement mortar will decrease. Therefore, the optimum the accelerating admixture content is 0.005 . 


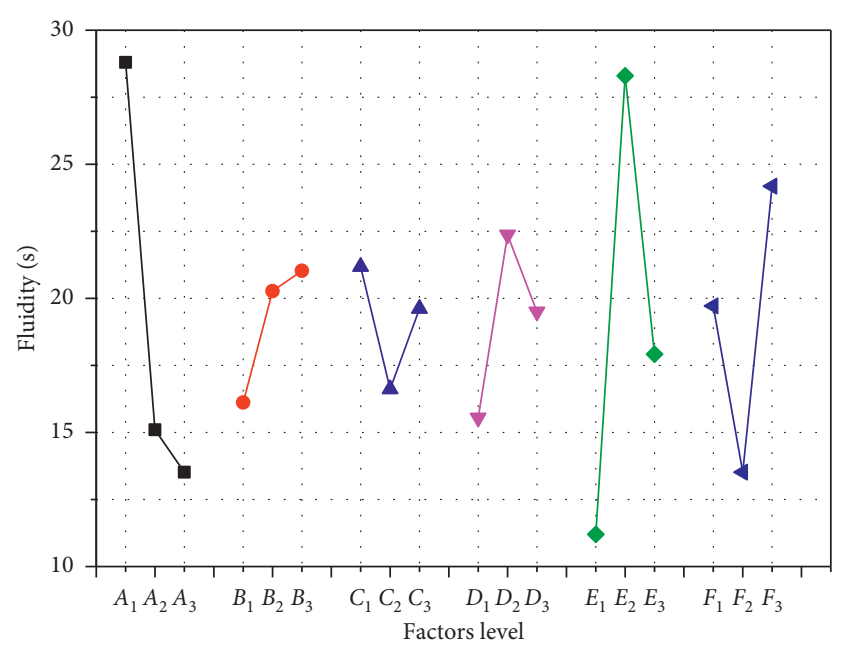

FIGURE 2: Influence tendencies of factors on fluidity of HPCM.

\subsection{Influence Tendencies of Factors on Drying Shrinkage of} HPCM. According to the experimental results, the influence tendencies of the factors on drying shrinkage are shown in Figure 3.

As shown in the figure, the drying shrinkage increases with the water-binder ratio, and the shrinkage rate is lower than $0.18 \%$. The drying shrinkage decreases first and then increases with the mineral powder content, and the shrinkage rate of HPCM is the lowest when the mineral powder content is 0.15 . Therefore, the optimum mineral powder content is 0.15 .

The drying shrinkage decreases with the increase of the sand-binder ratio, and the shrinkage rate changes little as the sand-binder ratio varies from 0.15 to 0.20 and decreases rapidly as the sand-binder ratio varies from 0.20 to 0.25 . So the optimum sand-binder ratio is 0.25 .

The drying shrinkage of HPCM is in an overall decreasing trend with the increasing of the content of expansion admixture. The drying shrinkage rate is the minimum when the expansion admixture content is 0.08 , a decrease of $39.65 \%$ compared to pure cement mortar. Therefore, the optimum expansion admixture content is 0.08 .

The drying shrinkage increases first and then decreases with the increase of the content of polycarboxylate superplasticizer content, the fluctuation is small, and the shrinkage rate does not exceed $0.18 \%$. The drying shrinkage decreases first and then increases with the accelerating admixture content, and the shrinkage rate is the lowest when the accelerating admixture content is 0.005 .

4.3. Influence Tendencies of Factors on Strength of HPCM. According to the experimental results, the influence tendencies of all factors on the strength of different curing times are shown in Figures 4 and 5.

As shown in the figures, the compressive strength of the cement mortar increases with the curing time, while the flexural strength at 28 days is slightly lower than that at 7 days. This is because that the adding of the accelerating

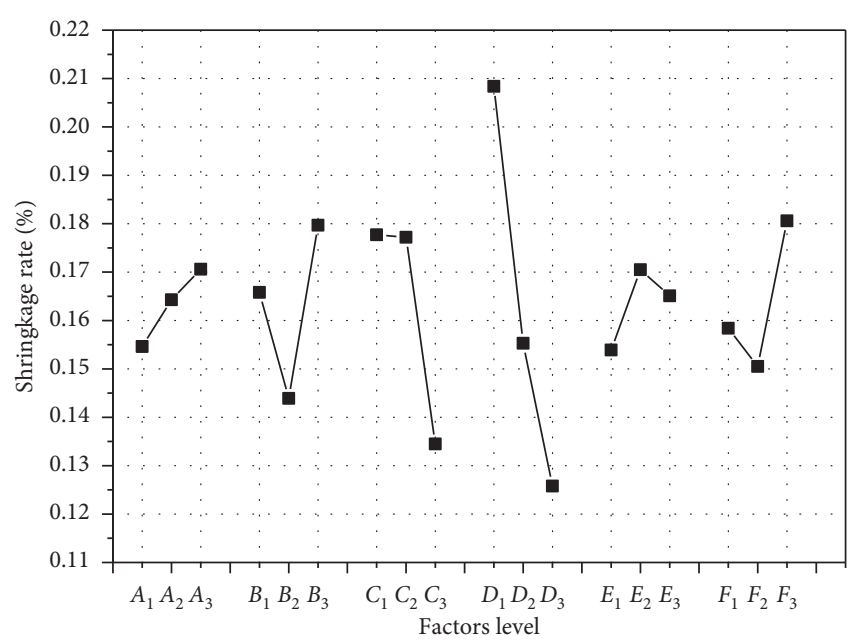

Figure 3: Influence tendencies of factors on drying shrinkage of HPCM.

admixture to the mortar results in a slight decrease in the flexural strength of the cement mortar in the later curing stage.

The effects of water-binder ratio on the strength of the cement mortar at different curing times are similar. They decrease with the increase of the water-binder ratio. The growth range of the strength of the cement mortar under the same water-binder ratio decreases with the increase of curing time. Therefore, the optimum range of the waterbinder ratio is $0.45-0.50$.

The flexural strength of the cement mortar at different curing times decreases first and then increases with the increase of the content of the mineral powder, and the compressive strength changes slowly. The flexural strength of the mortar is the lowest, and the compressive strength is high when the content of the mineral powder is 0.15 .

The strength of the cement mortar increases gradually with the increase of the sand-binder ratio. The rangeability of the strength increases with curing time as the sand-binder ratio varies from 0.20 to 0.25 , and this indicates that the standard sand can increase the later strength of the cement mortar in the range. Therefore, the optimum range of the sand-binder ratio is $0.20-0.25$.

The increasing range of the flexural strength is much greater than that of the compressive strength after adding the expansion admixture. The rangeability of strength of the cement mortar is more stable when the expansion admixture content varies from 0.004 to 0.008 . However, the increase in the flexural strength in the later curing stage is inhibited.

The compressive and flexural strengths of the cement mortar are greatly improved by adding the polycarboxylate superplasticizer. The effects of the superplasticizer content in the range of $0-0.01$ on the strengths in the later curing stage are similar. The strength of the cement mortar at 1 day decreases first and then increases slowly with the curing time as the polycarboxylate superplasticizer content varies from 0.005 to 0.01 . This indicates that the strength of the cement mortar in short curing time is lower, and in the later curing stage, the strength increases with the polycarboxylate 


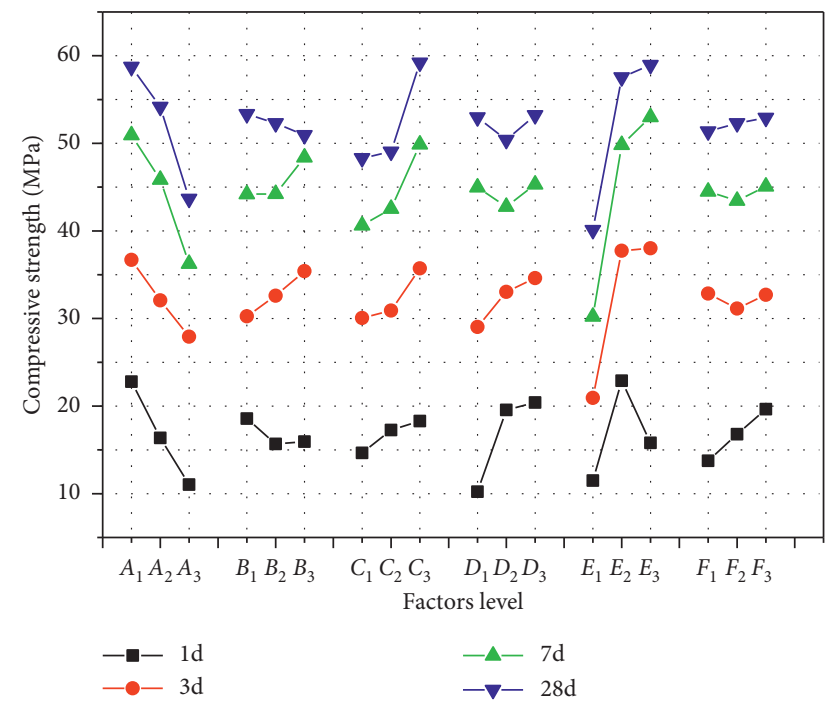

FIGURE 4: Influence tendencies of factors on compressive strength of different curing times of HPCM.

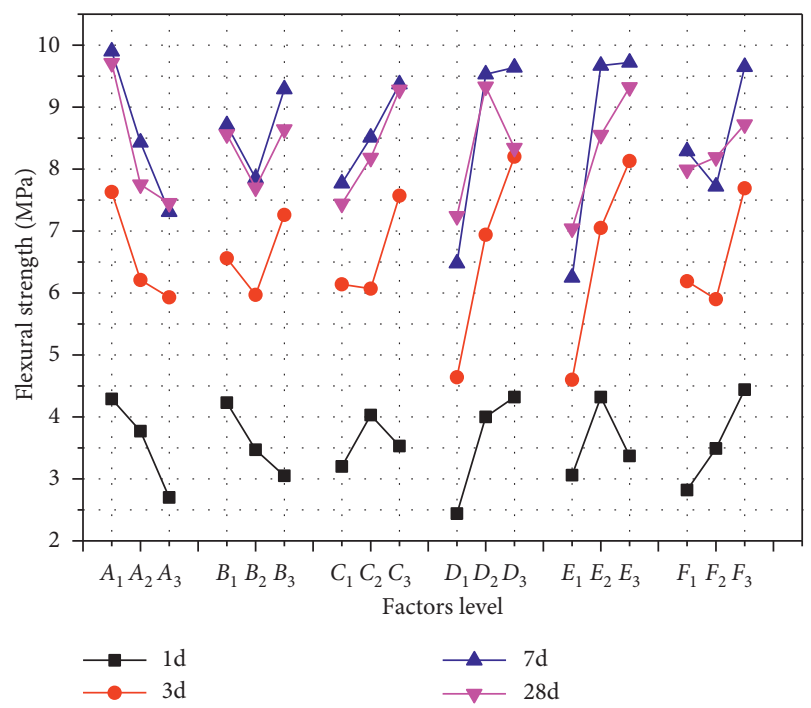

FIGURE 5: Influence tendencies of factors on flexural strength of different curing times of HPCM.

superplasticizer content. Therefore, the optimum polycarboxylate superplasticizer content is 0.01 .

The strength of the mortar in short curing time can be increased by adding the accelerating admixture. However, the strengths at 3 days and 7 days of the cement mortar decrease first and then increase with the content. The rangeability of the mortar strength is smaller as the accelerating admixture content varies from 0 to 0.005 , and the strength increases greatly as the content of the accelerating admixture varies from 0.005 to 0.01 . Therefore, the optimum range of the accelerating admixture content is $0.005-0.01$.

4.4. Optimal Formulations of HPCM. The recommended value of the factors were obtained and are listed in Table 6, taking into account the influence tendencies of all factors on the properties of HPCM.

The cement mortar was remixed, and its performance was tested according to the recommended ratios for HPCM, and the results are shown in Table 7. The research results of cement mortar in China and abroad are summarized and are shown in Table 7 [18]. Table 7 shows that HPCM has higher early strength, and the strength at 1 day reaches about $17 \mathrm{MPa}$; the strength development is stable in the later period, and strength at 7 days reaches 1.3 to 4 times of the current results; the volume stability far outperforms the existing specifications, and the dry shrinkage rates are less than 0.2 .

\section{Research on Grouting Effect of HPCM}

The high-temperature performance of the specimen after grouting was used as the evaluation index to study the relationship between the grouting rates and the dynamic stability, so as to determine the grouting rate of highperformance cement mortar. In addition, the properties of the semiflexible material were verified by the lowtemperature bending test and freeze-thaw splitting test.

5.1. High-Temperature Rutting Test of HPCM. The grouting rates of three kinds of cement mortar with different masses were calculated by Equation (1). The semiflexible material specimens were manufactured according to the method in Section 2.2, the dynamic stabilities of the semiflexible materials with different grouting rates were measured by the rutting tests, and the results are listed in Table 8.

Table 8 shows that the dynamic stability of the semiflexible material M1 at each grouting rate is greater than that of M2 and M3, while the rutting depth of M1 is smaller, and this indicates that M1 has the best rutting resistance. The dynamic stabilities of the three grouting materials are more than 10,000 times $/ \mathrm{mm}$ as the grouting rate is greater than $90 \%$, meeting the specification requirements.

Figure 6 shows the dynamic stabilities of the grouting materials at different grouting rates. As can be seen, the dynamic stabilities of the three grouting materials have the same growth tendency. The increasing rate of the dynamic stabilities gradually increases with the grouting rates.

The above results show that the rutting resistance of semiflexible materials increases with the increase of the grouting rate. The dynamic stability of the semiflexible material is more than 10000 times $/ \mathrm{mm}$ as the grouting rate is greater than $90 \%$.

5.2. Low-Temperature Bending Test of HPCM. The lowtemperature bending properties of three kinds of grouting materials with different grouting rates are measured based on the results of high-temperature rutting test, and the lowtemperature properties of these three semiflexible materials are verified. The experimental results are listed in Table 9.

Table 9 shows that the flexural tensile strength and the stiffness modulus of semiflexible materials increase regularly and the strain decreases regularly with the increase of 
TABLE 6: Results of the recommended value and selected ratios of HPCM.

\begin{tabular}{|c|c|c|c|c|c|c|c|}
\hline & & $A$ & $B$ & $C$ & $D$ & $E$ & $F$ \\
\hline Fluidity & & $0.5-0.55$ & 0.1 & 0.2 & $\geq 0.08$ & $\geq 0.01$ & 0.005 \\
\hline Drying shrinkage & & $\leq 0.55$ & $0.1-0.15$ & $0.2-0.25$ & $0.04-0.08$ & $\geq 0.01$ & 0.005 \\
\hline Strength & & $0.45-0.5$ & 0.15 & $0.2-0.25$ & $0.04-0.08$ & 0.01 & $0.005-0.01$ \\
\hline Recommended value range & & $0.5-0.55$ & $0.1-0.15$ & $0.2-0.25$ & 0.008 & 0.01 & 0.005 \\
\hline \multirow{3}{*}{ Recommend ratios of HPCM } & M1 & 0.5 & 0.1 & 0.2 & 0.08 & 0.01 & 0.005 \\
\hline & M2 & 0.55 & 0.1 & 0.25 & 0.08 & 0.01 & 0.005 \\
\hline & M3 & 0.55 & 0.15 & 0.25 & 0.08 & 0.01 & 0.005 \\
\hline
\end{tabular}

TABLE 7: Test results of HPCM with the recommend ratio.

\begin{tabular}{|c|c|c|c|c|c|c|c|c|c|c|}
\hline \multirow[b]{2}{*}{ Results } & \multirow[b]{2}{*}{ Fluidity (s) } & \multicolumn{2}{|c|}{1 day strength $(\mathrm{MPa})$} & \multicolumn{2}{|c|}{3 days' strength $(\mathrm{MPa})$} & \multicolumn{2}{|c|}{7 days' strength $(\mathrm{MPa})$} & \multicolumn{2}{|c|}{28 days' strength $(\mathrm{MPa})$} & \multirow{2}{*}{$\begin{array}{l}60 \text { days' } \\
\text { shrinkage } \\
\text { ratio }(\%)\end{array}$} \\
\hline & & $\begin{array}{l}\text { Flexural } \\
\text { strength }\end{array}$ & $\begin{array}{c}\text { Compressive } \\
\text { strength }\end{array}$ & $\begin{array}{l}\text { Flexural } \\
\text { strength }\end{array}$ & $\begin{array}{c}\text { Compressive } \\
\text { strength }\end{array}$ & $\begin{array}{l}\text { Flexural } \\
\text { strength }\end{array}$ & $\begin{array}{c}\text { Compressive } \\
\text { strength }\end{array}$ & $\begin{array}{l}\text { Flexural } \\
\text { strength }\end{array}$ & $\begin{array}{c}\text { Compressive } \\
\text { strength }\end{array}$ & \\
\hline M1 & 13.4 & 1.55 & & 4.90 & & & & & & 0.1919 \\
\hline M2 & 11.9 & 1.85 & 21.28 & 5.20 & 34.60 & 5.70 & & 7.82 & 5.93 & 0.1883 \\
\hline M3 & 12.7 & 1.30 & 17.03 & 5.10 & 32.63 & 5.8 & 42.98 & 7.51 & 54.53 & 0.1845 \\
\hline Range & $10 \sim 14$ & - & - & - & - & $\geq 2$ & $10 \sim 30$ & $\geq 4$ & $20 \sim 50$ & $-0.5 \sim 0.5$ \\
\hline
\end{tabular}

TABLE 8: Rutting test results with different grouting rates.

\begin{tabular}{|c|c|c|c|c|c|c|}
\hline \multirow{2}{*}{$\begin{array}{l}\text { Grouting } \\
\text { rates }(\%)\end{array}$} & \multicolumn{2}{|c|}{ M1 } & \multicolumn{2}{|c|}{ M2 } & \multicolumn{2}{|c|}{ M3 } \\
\hline & $\begin{array}{c}\text { Dynamic stability } \\
(\text { Times } / \mathrm{mm})\end{array}$ & $\begin{array}{c}\text { Rutting } \\
\text { depth }(\mathrm{mm})\end{array}$ & $\begin{array}{c}\text { Dynamic stability } \\
(\text { Times } / \mathrm{mm})\end{array}$ & $\begin{array}{c}\text { Rutting } \\
\text { depth }(\mathrm{mm})\end{array}$ & $\begin{array}{c}\text { Dynamic stability } \\
\text { (Times } / \mathrm{mm})\end{array}$ & $\begin{array}{c}\text { Rutting } \\
\text { depth (mm) }\end{array}$ \\
\hline 70 & 9448 & 1.92 & 8034 & 2.16 & 9072 & 1.94 \\
\hline 80 & 12058 & 1.47 & 9393 & 1.89 & 10488 & 1.62 \\
\hline 90 & 19481 & 1.28 & 14024 & 1.49 & 16918 & 1.41 \\
\hline 100 & 28984 & 1.14 & 23821 & 1.41 & 26624 & 1.27 \\
\hline
\end{tabular}

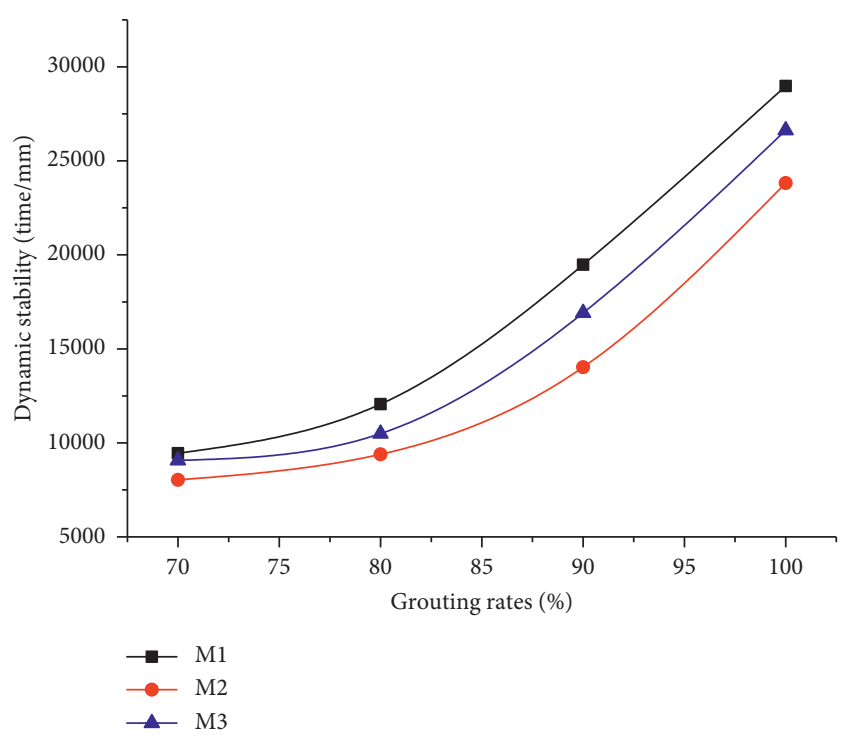

FIGURE 6: Relationships between dynamic stabilities and grouting rates.

grouting rates. The increase of grouting rates increases the stiffness of the semiflexible material so that the deformation is reduced and the bending strength is increased.

With the increase of grouting rates, the content of cement mortar in semiflexible material increases, which makes the overall stiffness of the material increase. The ability of the material to resist loads increases, and brittle fracture occurs easily when failure occurs as the stiffness of the semiflexible material increases. Therefore, the flexural strength and the flexural stiffness modulus of semiflexible materials increase with the increase of the grouting rate.

5.3. Freeze-Thaw Splitting Test of HPCM. Water damage is one of the main problems of the road surface and one of the important causes of early pavement damage. The tensile strength ratio (TSR) was used to characterize the water damage resistance of pavement. The freeze-thaw splitting test results are listed in Table 10.

Table 10 shows that the splitting strength of the semiflexible material is increased by $10 \%$ when the grouting rate is $90 \%$; the splitting strength of the semiflexible material is increased by $17 \%$ when the grouting rate is $100 \%$. The indirect tensile strength and the TSR of the semiflexible material increase regularly with the increase of the grouting rates. The tensile strength ratio is greater than $85 \%$ when the grouting rate is greater than $90 \%$, which meets the technical requirements of the current standard for pavement moisture susceptibility.

With the increase of the grouting rates, the content of cement mortar in semiflexible materials increases. The strength of the semiflexible material is composed of asphalt concrete and cement mortar. With the increase of the 
TABLE 9: Low-temperature bending test results.

\begin{tabular}{lccccccccc}
\hline $\begin{array}{l}\text { Grouting } \\
\text { rates }\end{array}$ & Strain $(\mu \varepsilon)$ & $\begin{array}{c}\text { M1 } \\
\text { Stress } \\
(\mathrm{MPa})\end{array}$ & $\begin{array}{c}\text { Stiffness } \\
\text { modulus }(\mathrm{MPa})\end{array}$ & Strain $(\mu \varepsilon)$ & $\begin{array}{c}\text { M2 } \\
\text { Stress } \\
(\mathrm{MPa})\end{array}$ & $\begin{array}{c}\text { Stiffness } \\
\text { modulus (MPa) }\end{array}$ & $\begin{array}{c}\text { M3 } \\
\text { Strain }(\mu \varepsilon)\end{array}$ & $\begin{array}{c}\text { Stress } \\
(\mathrm{MPa})\end{array}$ & $\begin{array}{c}\text { Stiffness } \\
\text { modulus }(\mathrm{MPa})\end{array}$ \\
\hline $80 \%$ & 2195.55 & 7.42 & 3379.56 & 2106.49 & 7.06 & 3351.55 & 2070.28 & 6.53 & 3154.16 \\
$90 \%$ & 2052.53 & 7.67 & 3736.59 & 2023.45 & 7.48 & 3696.66 & 2046.55 & 7.34 & 3586.52 \\
$100 \%$ & 1987.46 & 8.65 & 4352.29 & 1964.92 & 8.45 & 4300.43 & 1927.83 & 8.02 & 4160.12 \\
\hline
\end{tabular}

TABLE 10: Freeze-thaw splitting test results.

\begin{tabular}{|c|c|c|c|c|c|c|c|c|c|}
\hline \multirow[b]{2}{*}{$\begin{array}{l}\text { Grouting } \\
\text { rates }\end{array}$} & \multicolumn{3}{|c|}{ M1 } & \multicolumn{3}{|c|}{ M2 } & \multicolumn{3}{|c|}{ M3 } \\
\hline & $\begin{array}{l}\text { Strength before } \\
\text { freeze-thaw } \\
\text { cycle (MPa) }\end{array}$ & $\begin{array}{l}\text { Strength after } \\
\text { freeze-thaw } \\
\text { cycle }(\mathrm{MPa})\end{array}$ & TSR (\%) & $\begin{array}{l}\text { Strength } \\
\text { before } \\
\text { freeze-thaw } \\
\text { cycle }(\mathrm{MPa})\end{array}$ & $\begin{array}{l}\text { Strength after } \\
\text { freeze-thaw } \\
\text { cycle }(\mathrm{MPa})\end{array}$ & TSR (\%) & $\begin{array}{l}\text { Strength } \\
\text { before } \\
\text { freeze-thaw } \\
\text { cycle }(\mathrm{MPa})\end{array}$ & $\begin{array}{l}\text { Strength after } \\
\text { freeze-thaw } \\
\text { cycle }(\mathrm{MPa})\end{array}$ & TSR (\%) \\
\hline $80 \%$ & 1.784 & 1.407 & 78.9 & 1.721 & 1.376 & 80.0 & 1.684 & 1.331 & 79.0 \\
\hline $90 \%$ & 1.843 & 1.595 & 86.5 & 1.793 & 1.563 & 87.2 & 1.738 & 1.485 & 85.4 \\
\hline $100 \%$ & 1.985 & 1.874 & 94.4 & 1.936 & 1.839 & 95.0 & 1.873 & 1.739 & 92.8 \\
\hline
\end{tabular}

cement mortar content, the proportion of cement mortar strength in the semiflexible material is increased, and the stability of the material is improved. Therefore, the TSR of the semiflexible material increases with the increase of the grouting rate.

The above results show that the semiflexible material has better high-temperature performance when the grouting rate is greater than $90 \%$. And the low-temperature bending test and the freeze-thaw splitting test are carried out to verify that the semiflexible material has good pavement performance when the grouting rate is greater than $90 \%$.

\section{Conclusions}

The high-performance cement mortar was used as the grouting material for semiflexible pavement in this paper. The influences of the factors on the performance of HPCM were analyzed, the optimum formulas were determined, and the best formulas for grouting rate were obtained through rutting experiments. The main conclusions drawn are as follows:

(1) The water-binder ratio, the mineral powder content, the sand-binder ratio, the expansion admixture content, the polycarboxylate superplasticizer content, and the accelerating admixture content have quite different effects on the performance of the grouting materials. The polycarboxylate superplasticizer content and the water-binder ratio have the most significant effects on the workabilities and the strengths. The expansion admixture content has the most significant effects on the dry shrinkage and the strengths in the early curing stages. The accelerating admixture content has a greater impact on the strength in the early curing stages, and the sandbinder ratio has a greater effect on the strength in the later curing stage.

(2) The recommended water-binder ratio, the content of the mineral powder, the sand-binder ratio, the content of the expansion admixture, the content of the polycarboxylate superplasticizer, and the content of the accelerating admixture are 0.5-0.55, 0.1-0.15, $0.2-0.25,0.008,0.01$, and 0.005 , respectively, in the research.

(3) Three optimal formulations of HPCM were designed and compared to the existing specifications. The materials M1, M2, and M3 have good workabilities and higher early strengths, the dry shrinkage rates are less than 0.2 , and the strengths at 7 days are 1.3 to 4 times that of existing specifications.

(4) Three kinds of designed grouting materials were poured into the porous asphalt mixture to study the rutting resistance of the semiflexible materials with different grouting rates. The grouting rate of the semiflexible material was determined by the hightemperature rutting test and then verified by the lowtemperature bending test and freeze-thaw splitting test. The results show that the semiflexible material has better pavement performance when the grouting rate is more than $90 \%$.

\section{Data Availability}

The data used to support the findings of this study are available from the corresponding author upon request.

\section{Conflicts of Interest}

The authors declare no conflict of interest.

\section{Authors' Contributions}

Yazhen Sun organized the research, Min Ding and Yuanyuan Cheng performed the cement mortar tests, Yazhen Sun and Yuanyuan Cheng wrote the manuscript, and Xuezhong Yuan and Jinchang Wang checked the manuscript. 


\section{Acknowledgments}

This research was performed at the Shenyang Jianzhu University, Institute of Transportation Engineering of Zhejiang University, and Zhejiang Scientific Research Institute of Transport. The research is funded by the National Natural Science Foundation(51478276), the Natural Science Foundation of Liaoning Province(20170540770), and the Zhejiang Provincial Highway Bureau Project (2018H25).

\section{References}

[1] F. M. Nejad, A. Azarhoosh, G. H. Hamedi, and H. Roshani, "Rutting performance prediction of warm mix asphalt containing reclaimed asphalt pavements," Road Materials and Pavement Design, vol. 15, no. 1, pp. 207-219, 2014.

[2] J. Zhang, J. Cai, J. Pei, R. Li, and X. Chen, "Formulation and performance comparison of grouting materials for semiflexible pavement," Construction and Building Materials, vol. 115, pp. 582-592, 2016.

[3] S. Koting, M. R. Karim, H. B. Mahmud, and N. A. A. Hamid, "Mechanical properties of cement-bitumen composites for semi-flexible pavement surfacing," Baltic Journal of Road and Bridge Engineering, vol. 9, no. 2, pp. 191-199, 2014.

[4] P. Chiara, B. Giacomo, G. Tullio, and M. Alessandro, "Preliminary in-situ evaluation of an innovative, semi-flexible pavement wearing course mixture using fast falling weight deflectometer," Materials, vol. 11, no. 4, p. 611, 2018.

[5] A. Setyawana, "Assessing the compressive strength properties of semi-flexible pavements," Procedia Engineering, vol. 54, pp. 863-874, 2013.

[6] N. M. Husain, M. R. Karim, H. B. Mahmud et al., "Effects of aggregate gradation on the physical properties of semiflexible pavement," Advances in Materials Science and Engineering, vol. 2014, Article ID 529305, 8 pages, 2014.

[7] B. Christian, H. Anders, and T. Finn, "Establishing a mechanistic/incremental design method for semi-rigid pavements through HVS testing," in Proceedings of Pavement Mechanics and Performance, Shanghai, China, January, 2006.

[8] R. J. Pelland, J. S. Gould, and R. B. Mallick, "Selecting a rut resistant hot mix asphalt for Boston-Logan international airport," in Proceedings of Airfield Pavements. Challenges and New Technologies, pp. 390-408, Las Vegas, NV, USA, September 2004.

[9] I. J. Huddleston, H. Zhou, and R. G. Hicks, "Evaluation of open-graded asphalt concrete mixtures used in oregon," Transportation Research Record, vol. 60, 1993.

[10] B. Yang and X. Weng, "The influence on the durability of semi-flexible airport pavement materials to cyclic wheel load test," Construction and Building Materials, vol. 98, pp. 171175,2015

[11] S. E. Zoorob, K. E. Hassan, and A. Setyawan, "Cold mix, cold laid semi-flexible grouted macadams, mix design and properties," in Proceedings of 4th European Symposium on Performance of Bituminous and Hydraulic Materials in Pavement, Bitmat, pp. 105-112, Nottingham, UK, 2002.

[12] M. D. Beer and F. Netterberg, "Weak interlayers inflexible and semi-flexible road pavements :part 1:technical paper," Journal of the South African Institution of Civil Engineering, vol. 54, pp. 32-42, 2012.

[13] M. D. Beer, J. W. Maina, and F. Netterberg, "Mechanistic modelling of weak interlayers in flexible and semi-flexible road pavements: part 2," Journal of the South African
Institution of Civil Engineering, vol. 54, no. 1, pp. 43-54, 2012.

[14] P. Dalin, Z. Xiaoning, and W. Shulin, Design Method of Asphalt Mixture Based on Semi-flexible Pavement, vol. 1, pp. 22-23, Central South Highway Engineering, Changsha, China, 2000.

[15] L. Tianqing, Z. Xiaowei, and L. Meng, "Research on performance of water-retention and temperature-fall semi-flexible pavement material," China Journal of Highway and Transport, vol. 23 , no. 2, pp. 7-11, 2010.

[16] W. Weiming, G. Dan, and W. Kuanghuai, "The research of performance on semi flexible pavement materials," Highway Engineering, China, vol. 39, no. 1, pp. 78-82, 2014.

[17] T. Feng, "Research on perfusion composite mortar of cement grouting semi- flexible pavement mixtures," Concrete, China, vol. 6, pp. 97-102, 2016.

[18] W. Wei, H. Huiming, W. Ruxi, L. Meidan, and W. Wei, "Optimization design principle of poured cement slurry ratio for semi-flexible pavement," Journal of Highway and Transportation Research and Development, China, vol. 34, no. 5, pp. 35-41, 2017.

[19] G. Xiaoyan, L. Lingxi, and C. Zhiqiang, "Study on flow performance of cement based grouting material for semiflexible pavement," Highway, China, vol. 62, no. 7, pp. 280285, 2017.

[20] W. Dongqing, Daud, and Z. Yanli, "The semi-rigid pavement with higher performances for roads and parking aprons," Sustainable Urbanization-Engineering Challenges and Opportunities, vol. 9, pp. 27-30, 2011.

[21] L. Tianqing, Z. Jie, Z. Zhijie, L. Changzhu, and D. Yingying, "Study on optimization of polymer modified cement slurry for poured semi-flexible pavement," Journal of Highway and Transportation Research and Development, China, vol. 26, no. 6, pp. 24-28, 2009.

[22] Z. Fu, Q. Liu, and K. M. Niu, Test Method of Cement and Concrete for Highway Engineering (JTG E30-2005), China Communications Press, Beijing, China, 2005.

[23] L. Tianqing, Z. Zhijie, L. Changzhu, and D. Qiang, Technology Guide for Application of Semi-Flexible Pavement, China Academy of TransportationSciences, Beijing, China, 2009.

[24] C. Zhiqiang, K. Fansheng, and J. Rongrong, "Study on the bleeding performance of cement grouting material on semiflexible pavement," Journal of China and Foreign Highway, vol. 36, no. 4, pp. 276-279, 2016.

[25] S. Koting, M. R. Karim, H. Mahmud et al., "Effects of using silica fume and polycarboxylate-type superplasticizer on physical properties of cementitious grout mixtures for semiflexible pavement surfacing," Scientific World Journal, vol. 2014, no. 2, Article ID 596364, 7 pages, 2014. 


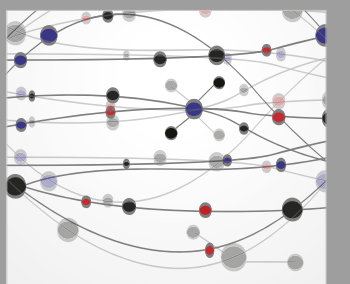

The Scientific World Journal
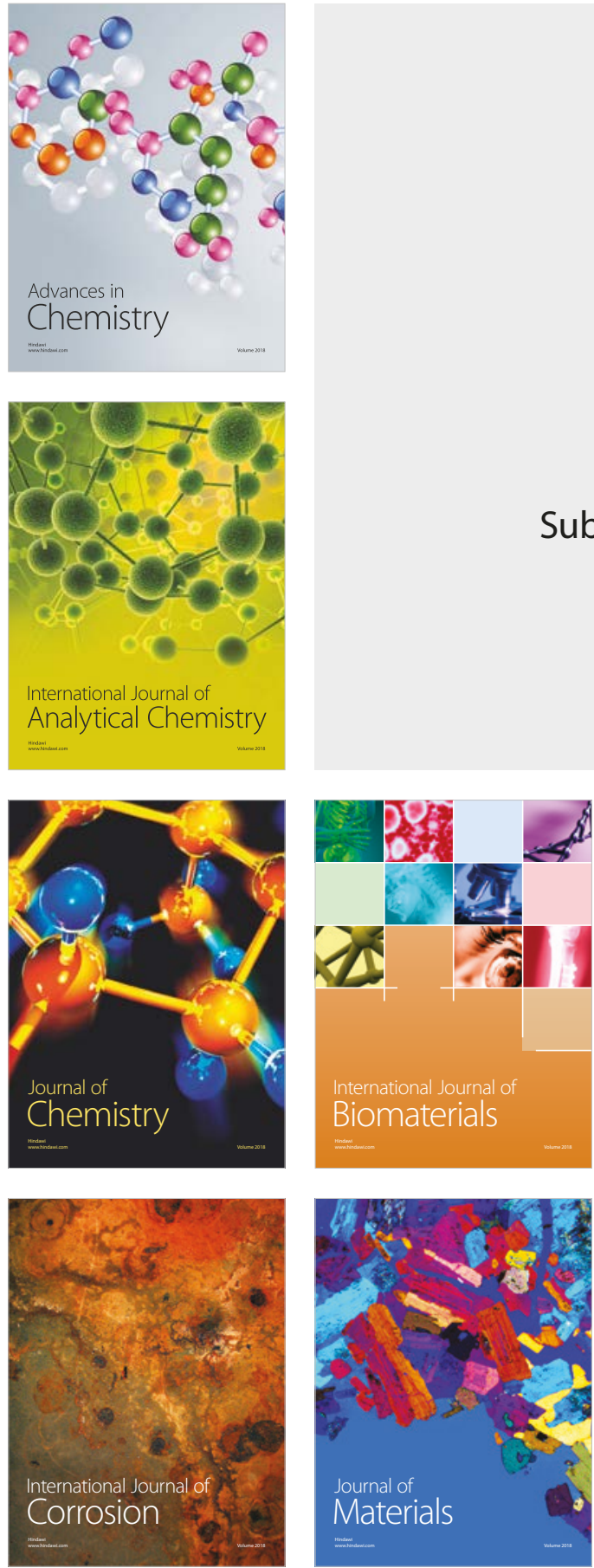

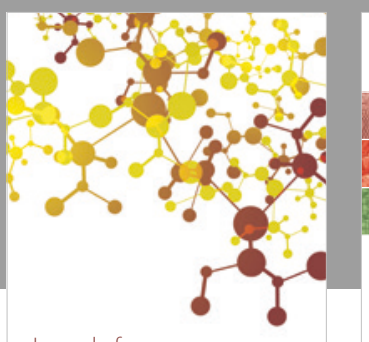

Journal of

Applied Chemistry
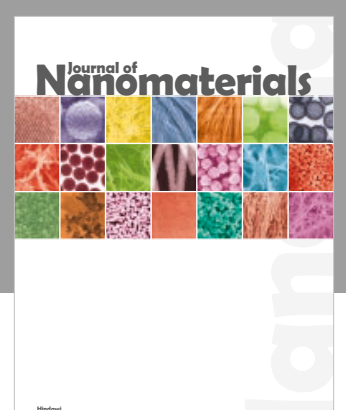

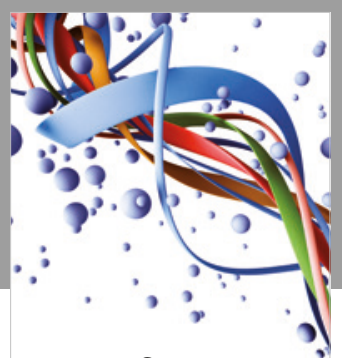

Scientifica

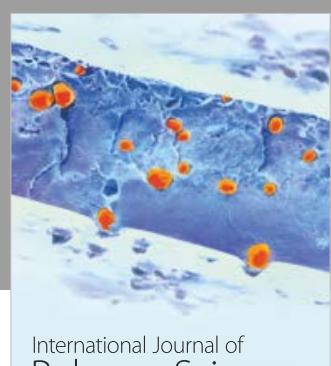

Polymer Science

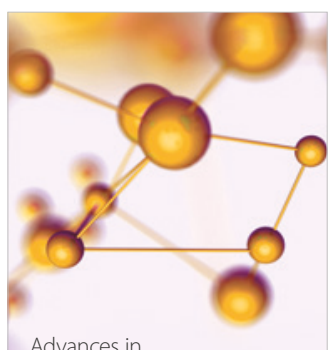

Physical Chemistry
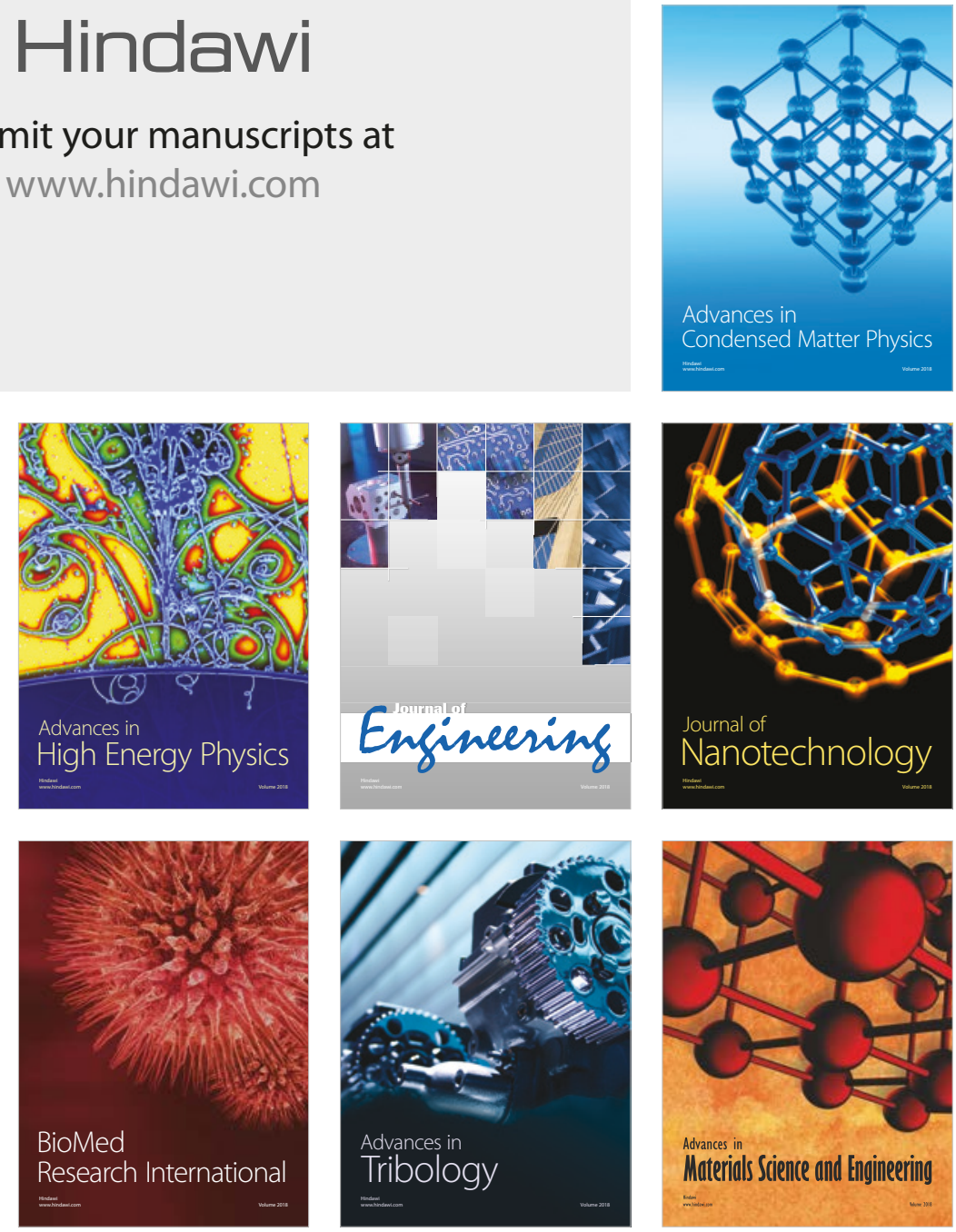